\title{
An Application of Machine Learning to Etiological Diagnosis of Secondary Hypertension: Retrospective Study Using Electronic Medical Records
}

Xiaolin Diao $^{1 *}$, MS; Yanni Huo ${ }^{1 *}$, MS; Zhanzheng Yan $^{1}$, MS; Haibin Wang ${ }^{1}$, ME; Jing Yuan ${ }^{2}$, ME; Yuxin Wang ${ }^{1}$, MS; Jun Cai ${ }^{3}$, MD; Wei Zhao ${ }^{2}$, PhD

\footnotetext{
${ }^{1}$ Department of Information Center, Fuwai Hospital, Chinese Academy of Medical Sciences and Peking Union Medical College, Beijing, China

${ }^{2}$ Department of Information Center, Fuwai Hospital, National Center for Cardiovascular Diseases, Chinese Academy of Medical Sciences and Peking Union Medical College, Beijing, China

${ }^{3}$ Hypertension Center, State Key Laboratory of Cardiovascular Disease, Fuwai Hospital, National Center for Cardiovascular Diseases, Chinese Academy of Medical Sciences and Peking Union Medical College, Beijing, China

*these authors contributed equally
}

\section{Corresponding Author:}

Wei Zhao, PhD

Department of Information Center, Fuwai Hospital

National Center for Cardiovascular Diseases

Chinese Academy of Medical Sciences and Peking Union Medical College

167 Beilishi Road

Beijing, 100037

China

Phone: 8613331192899

Email: zw@fuwai.com

\section{Abstract}

Background: Secondary hypertension is a kind of hypertension with a definite etiology and may be cured. Patients with suspected secondary hypertension can benefit from timely detection and treatment and, conversely, will have a higher risk of morbidity and mortality than those with primary hypertension.

Objective: The aim of this study was to develop and validate machine learning (ML) prediction models of common etiologies in patients with suspected secondary hypertension.

Methods: The analyzed data set was retrospectively extracted from electronic medical records of patients discharged from Fuwai Hospital between January 1, 2016, and June 30, 2019. A total of 7532 unique patients were included and divided into 2 data sets by time: 6302 patients in 2016-2018 as the training data set for model building and 1230 patients in 2019 as the validation data set for further evaluation. Extreme Gradient Boosting (XGBoost) was adopted to develop 5 models to predict 4 etiologies of secondary hypertension and occurrence of any of them (named as composite outcome), including renovascular hypertension (RVH), primary aldosteronism (PA), thyroid dysfunction, and aortic stenosis. Both univariate logistic analysis and Gini Impurity were used for feature selection. Grid search and 10-fold cross-validation were used to select the optimal hyperparameters for each model.

Results: Validation of the composite outcome prediction model showed good performance with an area under the receiver-operating characteristic curve (AUC) of 0.924 in the validation data set, while the 4 prediction models of RVH, PA, thyroid dysfunction, and aortic stenosis achieved AUC of $0.938,0.965,0.959$, and 0.946 , respectively, in the validation data set. A total of 79 clinical indicators were identified in all and finally used in our prediction models. The result of subgroup analysis on the composite outcome prediction model demonstrated high discrimination with AUCs all higher than 0.890 among all age groups of adults.

Conclusions: The ML prediction models in this study showed good performance in detecting 4 etiologies of patients with suspected secondary hypertension; thus, they may potentially facilitate clinical diagnosis decision making of secondary hypertension in an intelligent way. 


\section{KEYWORDS}

secondary hypertension; etiological diagnosis; machine learning; prediction model

\section{Introduction}

Hypertension is a common chronic disease worldwide, with $5 \%-10 \%$ of these patients being secondary hypertensive [1-5]. Patients with secondary hypertension who have high risks of morbidity and mortality if not diagnosed and treated timely are early onset cases, with higher blood pressure (BP) that is more difficult to be controlled than patients with primary hypertension [2-4,6]. Secondary hypertension identification is already known to benefit patients who have suggestive signs and symptoms, such as severe or resistant hypertension and an acute rise in BP from previously stable readings [1-3,5]. It is necessary to focus on accurate diagnosis to capture the secondary hypertension of patients in order to provide effective evidence for clinical therapy [2-4,7].

Artificial intelligence (AI) is seen as having the potential to provide more efficient medical services and has been applied in medical care, such as disease diagnosis, risk stratification, and health management [8-21]. AI technologies, especially machine learning (ML), have received attention in the diagnosis and treatment of hypertension. However, previous studies were focused on predicting future risks of hypertension and building clinical decision support systems to support early screening and treatment [22-31]. In addition, there are no relevant published studies on AI model-aided diagnosis of secondary hypertension for detecting etiologies of disease and providing effective treatment.

Accordingly, we used electronic medical record (EMR) data from Fuwai Hospital, a large, urban teaching hospital affiliated with Peking Union Medical College in Beijing, China, to develop ML diagnosis models of common etiologies of secondary hypertension and validate the feasibility and effectiveness of such models in assisting clinical diagnosis of secondary hypertension [32]. This study, based on representative and nationwide in-patient data, is ideally positioned to generate information to construct diagnosis-aided models for secondary hypertension during hospitalization.

\section{Methods}

\section{Study Population}

Our study consecutively enrolled 9788 admissions from the Hypertension Center, Fuwai Hospital, from January 1, 2016, to June 30, 2019. The following data were collected: demographics, preadmission symptoms, comorbidities, medication history of antihypertension, operation history, physical examination indicators, prehospital and intrahospital BP, intrahospital first laboratory test results, and computed tomography (CT) reports. For multiple visits of patients, only the first visits were taken into consideration, so we excluded 1687 re-admission records. A total of 569 patients without a definite diagnosis of primary hypertension or secondary hypertension at discharge were also excluded. The final analyzed data set included 7532 unique patients and was divided into 2 mutually exclusive data sets by time: 6302 patients in $2016-2018$ as the modeling data set for feature selection and model building, and 1230 patients in 2019 as the validation data set for subsequent evaluation and external verification (Figure 1). This study was approved by the Ethics Committee at Fuwai Hospital with the requirement for informed consent waived. Data used in this study were anonymous, and no identifiable personal data of the patients were used.

Figure 1. A workflow for patients inclusion and application.

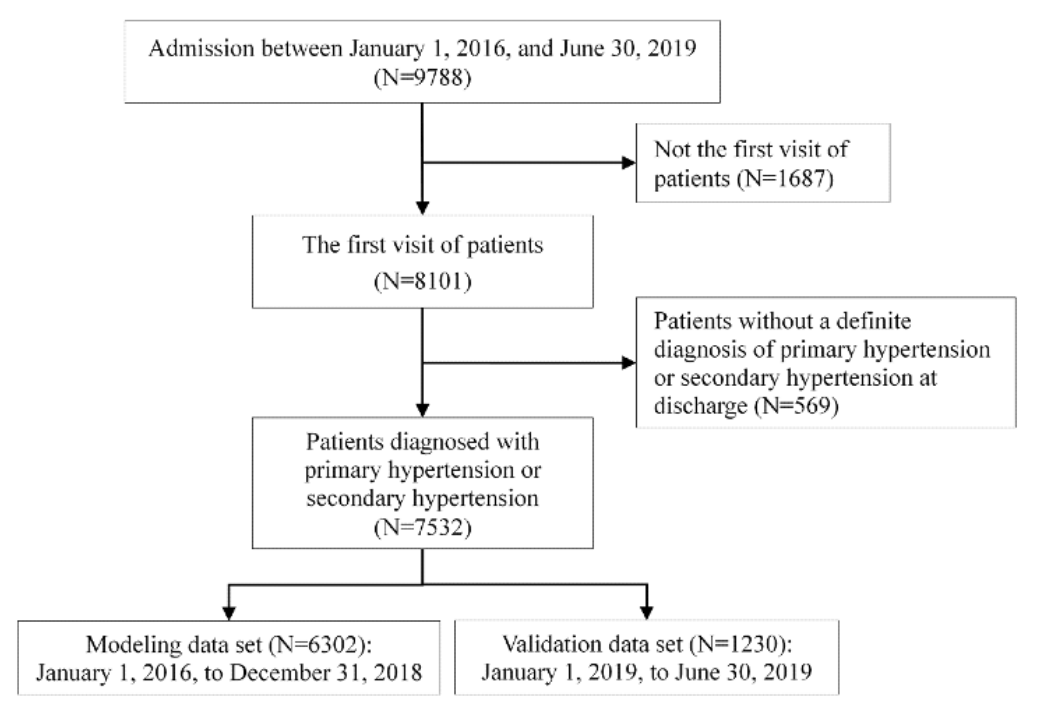

\section{Outcome Definitions}

Etiologies of secondary hypertension in this study were defined by the International Classification of Diseases, 10th Revision,
Clinical Modification (ICD-10-CM) diagnosis codes. Prediction models were developed for the following 5 outcomes chosen by the incidence rate: (1) renovascular hypertension (RVH), assigned the ICD-10-CM diagnosis code I15.001; (2) primary 
aldosteronism (PA), assigned the ICD-10-CM diagnosis code I15.201; (3) thyroid dysfunction, assigned the ICD-10-CM diagnosis codes E03.901 and E05.901; (4) aortic stenosis, assigned the ICD-10-CM diagnosis codes Q25.101, Q25.301, I77.102, I77.112, and I77.122; (5) composite outcome, defined as occurrence of any of (1)-(4).

\section{Data Processing}

We computed the maximum, minimum, and range among prehospital and intrahospital BP cases, respectively. The structured CT information was extracted from CT text reports using regular expressions and was standardized based on uniform medical terminology in cardiovascular medicine used in Fuwai Hospital. The capping method was used to deal with outliers in order to avoid the model performance being affected by potential input errors, and to retain most of the information. When there were missing values, we created an additional binary variable that assigned a value of 1 if missing and 0 otherwise. All continuous variables were converted to categorical variables by the smbinning package of R 3.4.4 software (R Foundation), which was a supervised binning method based on the conditional inference tree. All categorical variables were one-hot coded [33].

\section{Feature Selection}

Two kinds of feature selection methods were introduced successively in our study. First, we used univariate logistic analysis to eliminate features that were unlikely to predict the outcomes with a $P$-value threshold of .01 . Then, we randomly split modeling data set into training data set and test data set by $8: 2$, and conducted Gini Impurity to rank the contribution of features and only keep the top $20 \%$ of features as the final features for each outcome based on the training data set.

\section{Model Building}

Five ML models of 4 etiologies of secondary hypertension and 1 composite outcome were trained using the training data set. Before training, the synthetic minority oversampling technique was adopted to deal with the unbalanced issue of the training data set [34]. XGBoost (Extreme Gradient Boosting), an ensemble tree-based model, has been shown to be more likely to achieve better model performance and to be more interpretable than other ML models, such as logistic regression or support vector machine [35-39]. Therefore, we choose the XGBoost algorithm to develop the prediction model for each outcome. In order to avoid overfitting, we used grid search and 10-fold cross-validation to select the optimal hyperparameters (Figure 2).

For all outcomes, we compared the receiver operating characteristic curve and the area under the curve (AUC), accuracy, sensitivity, specificity, and precision to measure model performance in the test data set of the modeling data set and the validation data set. Furthermore, the accuracy of the composite outcome model on different age subgroups $(\leq 18,19-44,45-59$, and $\geq 60$ ) was evaluated. All analyses were performed using $R$ software version 3.4.4 (R Foundation for Statistical Computing).

Figure 2. Procedure flow of modeling. SMOTE: Synthetic Minority Oversampling Technique; XGBoost: extreme Gradient Boosting.

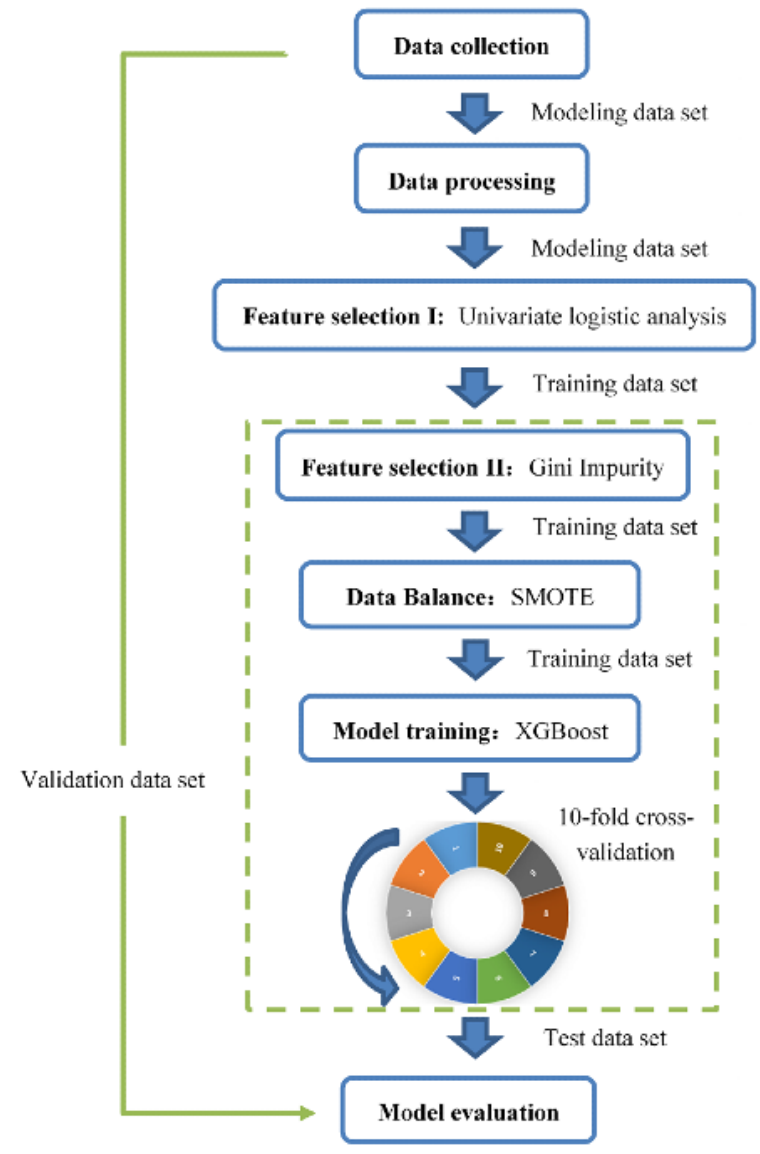




\section{Results}

\section{Baseline Characteristics}

Of the 7532 patients included in this study, $64.82 \%$ (4882/7532) were male, with a mean age of 47.70 (SD 14.77), a mean maximum systolic pressure of 173.00 (SD 29.50) $\mathrm{mmHg}$, and a mean maximum diastolic pressure of 124.87 (SD 32.56) mmHg. Among them, 72.48\% (5459/7532) were diagnosed with hypertension in the past, and $6.70 \%(505 / 7532), 5.31 \%$ (400/7532), 1.85\% (139/7532), and 0.94\% (71/7532) were diagnosed with RVH, PA, thyroid dysfunction, and aortic stenosis at discharge, respectively. As much as $13.95 \%$ $(1051 / 7532)$ of patients were diagnosed with any of the 4 etiologies at discharge (ie, with composite outcome). Most characteristics were similarly distributed between the 2 data sets (Table 1).

Table 1. Baseline characteristics.

\begin{tabular}{|c|c|c|c|}
\hline Characteristic & Modeling data set $(\mathrm{N}=6302)$ & Validation data set $(\mathrm{N}=1230)$ & All data set $(\mathrm{N}=7532)$ \\
\hline Male, n (\%) & $4089(64.88)$ & $793(64.47)$ & $4882(64.82)$ \\
\hline Age (years), mean (SD) & $47.74(14.80)$ & $47.48(14.61)$ & $47.70(14.77)$ \\
\hline BMI $\left(\mathrm{kg} / \mathrm{m}^{2}\right)$, mean $(\mathrm{SD})$ & $26.47(3.69)$ & $26.62(3.75)$ & $26.49(3.70)$ \\
\hline Maximum $\mathrm{SP}^{\mathrm{a}}(\mathrm{mmHg})$, mean (SD) & $172.57(29.96)$ & $175.20(26.96)$ & $173.00(29.50)$ \\
\hline Minimum SP (mmHg), mean (SD) & $110.46(28.95)$ & $107.99(29.72)$ & $110.06(29.09)$ \\
\hline Maximum $\mathrm{DP}^{\mathrm{b}}(\mathrm{mmHg})$, mean $(\mathrm{SD})$ & $124.15(32.85)$ & $128.53(30.77)$ & $124.87(32.56)$ \\
\hline Minimum DP (mmHg), mean (SD) & $79.45(12.62)$ & $79.14(12.55)$ & $79.40(12.61)$ \\
\hline \multicolumn{4}{|l|}{ Comorbidities } \\
\hline Hypertension, n (\%) & $4938(78.36)$ & $521(42.36)$ & $5459(72.48)$ \\
\hline Hyperlipemia, n (\%) & $2846(45.16)$ & $486(39.51)$ & $3332(44.24)$ \\
\hline Cerebrovascular disease, $\mathrm{n}(\%)$ & $1007(15.98)$ & $158(12.85)$ & $1165(15.47)$ \\
\hline Thyroid disease, $\mathrm{n}(\%)$ & $462(7.33)$ & $72(5.85)$ & $534(7.09)$ \\
\hline Hypokalemia, n (\%) & $106(1.68)$ & $24(1.95)$ & $130(1.73)$ \\
\hline \multicolumn{4}{|l|}{ Medication history of antihypertension } \\
\hline Nifedipine, $\mathrm{n}(\%)$ & $2056(32.62)$ & $400(32.52)$ & $2456(32.61)$ \\
\hline Amlodipine, n (\%) & $1776(28.18)$ & $340(27.64)$ & $2116(28.09)$ \\
\hline Verapamil hydrochloride, n (\%) & $1621(25.72)$ & $605(49.19)$ & $2226(29.55)$ \\
\hline Metoprolol, n (\%) & $1545(24.52)$ & $244(19.84)$ & $1789(23.75)$ \\
\hline Enalapril maleate, n (\%) & $346(5.49)$ & $50(4.07)$ & $396(5.26)$ \\
\hline \multicolumn{4}{|l|}{ Discharge diagnosis } \\
\hline $\mathrm{RVH}^{\mathrm{c}}, \mathrm{n}(\%)$ & $409(6.49)$ & $96(7.80)$ & $505(6.70)$ \\
\hline $\mathrm{PA}^{\mathrm{d}}, \mathrm{n}(\%)$ & $323(5.13)$ & $77(6.26)$ & $400(5.31)$ \\
\hline Thyroid dysfunction, n (\%) & $119(1.89)$ & $20(1.63)$ & $139(1.85)$ \\
\hline Aortic stenosis, n (\%) & $59(0.94)$ & $12(0.98)$ & $71(0.94)$ \\
\hline Composite outcome, n (\%) & $858(13.61)$ & $193(15.69)$ & $1051(13.95)$ \\
\hline
\end{tabular}

${ }^{\mathrm{a}} \mathrm{SP}$ : systolic pressure.

${ }^{\mathrm{b}} \mathrm{DP}$ : diastolic pressure.

${ }^{\mathrm{c}} \mathrm{RVH}$ : renovascular hypertension.

${ }^{\mathrm{d}} \mathrm{PA}$ : primary aldosteronism.

\section{Model Performance}

The 4 prediction models of secondary hypertension etiologies reached AUCs of 0.953-0.983 with sensitivities of 83.6\%-92.9\% and specificities of $89.9 \%-95.9 \%$ in the test data set of the modeling data set, whereas they achieved AUCs of 0.938-0.965 with sensitivities of $75.0 \%-90.0 \%$ and specificities of
$89.4 \%-97.3 \%$ in the validation data set. Among them, the prediction model of PA achieved the best model performance with AUC of 0.965 , sensitivity of $84.4 \%$, specificity of $93.0 \%$, and precision of $44.5 \%$ in the validation data set. The prediction model of composite outcome showed good performance in the test data set of the modeling data set with an AUC, sensitivity, specificity, and precision of $0.901,82.1 \%, 84.6 \%$, and $45.8 \%$, 
respectively, as well as in the validation data set with values of $0.924,85.5 \%, 86.2 \%$, and $53.6 \%$, respectively (Figure 3 and

Table 2).

Figure 3. ROC curves for prediction models in both data sets. (A) ROC curves for prediction models in the test data set of the modeling data set. (B) ROC curves for prediction models in the validation data set. AUC: area under ROC; ROC: receiver-operating characteristic curve.
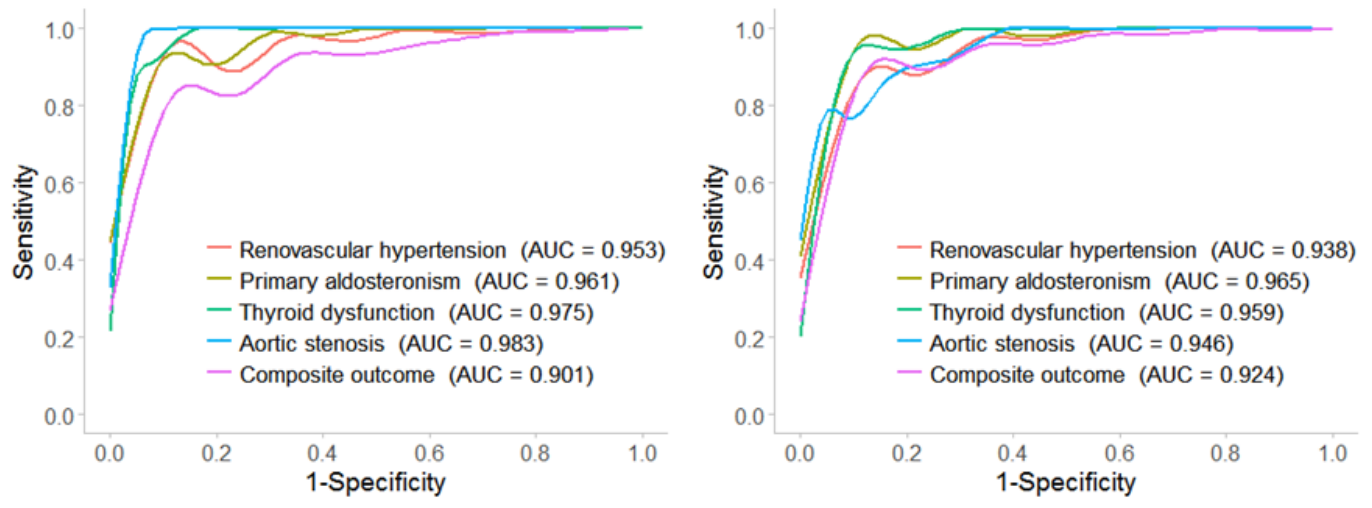

Table 2. Model performance.

\begin{tabular}{|c|c|c|c|c|c|}
\hline Outcomes & $\mathrm{AUC}^{\mathrm{a}}$ & Accuracy, $\%$ & Sensitivity, $\%$ & Specificity, \% & Precision, $\%$ \\
\hline \multicolumn{6}{|l|}{$\mathbf{R V H}^{\mathbf{b}}$} \\
\hline Test data set & 0.953 & 90.0 & 87.1 & 90.2 & 41.5 \\
\hline Validation data set & 0.938 & 88.9 & 83.3 & 89.4 & 40.0 \\
\hline \multicolumn{6}{|l|}{$\mathbf{P A}^{\mathbf{c}}$} \\
\hline Test data set & 0.961 & 95.3 & 83.6 & 95.9 & 47.9 \\
\hline Validation data set & 0.965 & 92.4 & 84.4 & 93.0 & 44.5 \\
\hline \multicolumn{6}{|l|}{ Thyroid dysfunction } \\
\hline Test data set & 0.975 & 90.0 & 92.9 & 89.9 & 17.3 \\
\hline Validation data set & 0.959 & 92.5 & 90.0 & 92.6 & 16.7 \\
\hline \multicolumn{6}{|l|}{ Aortic stenosis } \\
\hline Test data set & 0.983 & 95.5 & 90.0 & 95.5 & 13.8 \\
\hline Validation data set & 0.946 & 97.1 & 75.0 & 97.3 & 21.4 \\
\hline \multicolumn{6}{|l|}{ Composite outcome } \\
\hline Test data set & 0.901 & 84.2 & 82.1 & 84.6 & 45.8 \\
\hline Validation data set & 0.924 & 86.1 & 85.5 & 86.2 & 53.6 \\
\hline
\end{tabular}

${ }^{a}$ AUC: area under the receiver-operating characteristic curve.

${ }^{\mathrm{b}} \mathrm{RVH}$ : renovascular hypertension.

${ }^{\mathrm{c}} \mathrm{PA}$ : primary aldosteronism.

\section{Impactful Features}

A total of 362 clinical indicators were considered initially and a total of 79 indicators were finally included in our 5 prediction models, 46 of which were included in the prediction model of composite outcome, and 33, 21, 14, and 14 were included in the prediction model of RVH, PA, thyroid dysfunction, and aortic stenosis, respectively. The remaining indicators included 2 demographic indicators, 3 preadmission symptoms, 5 BP indicators, 4 comorbidities, 5 antihypertension medications, 2 operation indicators, 3 physical examination indicators, 46 intrahospital first laboratory tests, and 9 indicators from CT reports (Multimedia Appendix 1). Each of the 4 prediction models of secondary hypertension etiologies had their own typical indicators of high contribution while only a few indicators were included in at least two prediction models. The indicators used in the composite outcome prediction model were mainly derived from the most important indicators of 4 etiology prediction models (Table 3). 
Table 3. Top 10 clinical indicators for prediction models.

Clinical indicators
$\mathbf{R V H}^{\mathbf{b}}$

Renal artery stenosis indicated by $\mathrm{CT}^{\mathrm{c}}$

Abnormalities of renal artery indicated by CT

Albumin-to-creatinine ratio ${ }^{\mathrm{d}}$

NT-proBNP ${ }^{\mathrm{e}}$

Cerebrovascular disease $\mathrm{f}^{\mathrm{f}}$

Abnormalities of adrenal glands indicated by CT

Maximum systolic pressure

Creatine kinase

The level of renal artery stenosis indicated by CT

Glutamyl transpeptidase

$\mathbf{P A}^{\mathbf{g}}$

Upright $\mathrm{ARR}^{\mathrm{h}}$

Serum potassium

Supine ARR

5.6

Supine plasma aldosterone

Upright plasma aldosterone

Glycated hemoglobin

Nifedipine

Albumin-to-creatinine ratio

24-hour urinary aldosterone

Serum sodium

Thyroid dysfunction

Thyroid disease

Thyrotropin

Prealbumin

Free thyroxine

Range of systolic pressure

1.2

Metoprolol

Palpitation

1.2

Surgery

1.0

Dizzy

Thyroid microsomal antibody

Aortic stenosis

Carotid bruits

Age

Vascular bruits

BMI

Aortic wall thickening or stenosis indicated by CT 


\begin{tabular}{ll}
\hline Clinical indicators & Contribution $^{\mathrm{a}}, \%$ \\
\hline Smoking status & 3.9 \\
Glomerular filtration rate & 3.7 \\
Supine plasma aldosterone & 1.6 \\
Range of systolic pressure & 0.9 \\
Composite outcome & 26.9 \\
Renal artery stenosis indicated by CT & 16.5 \\
Upright ARR & 10.0 \\
Thyroid disease & 6.0 \\
Serum potassium & 4.4 \\
Albumin-to-creatinine ratio & 3.4 \\
Supine ARR & 2.5 \\
Supine plasma aldosterone & 2.5 \\
Nifedipine & 1.9 \\
Hemoglobin concentration & 1.9 \\
Maximum systolic pressure & 2.5 \\
\hline
\end{tabular}

${ }^{\text {a }}$ The contribution represents the proportion of the information gain of each indicator in the total information gain of all indicators. The total contribution of all indicators included in each prediction model is 1 . The higher the contribution, the more important the indicator in the model.

${ }^{\mathrm{b}} \mathrm{RVH}$ : renovascular hypertension.

${ }^{\mathrm{c}} \mathrm{CT}$ : computed tomography.

${ }^{\mathrm{d}}$ All the laboratory test indicators were the first intrahospital laboratory test data of patients.

${ }^{\mathrm{e}}$ NT-proBNP: N-terminal probrain natriuretic peptide.

${ }^{\mathrm{f}}$ All the symptoms and medical and treatment history were reported by patients themselves upon admission.

${ }^{\mathrm{g}} \mathrm{PA}$ : primary aldosteronism.

${ }^{\mathrm{h}} \mathrm{ARR}$ : aldosterone-to-renin ratio.

\section{Subgroup Analysis}

The validation of the composite outcome prediction model in different age groups showed good discrimination with AUCs greater than 0.8 in all groups and sensitivities greater than $80 \%$ in all groups of adults (Table 4). It should be noted that sensitivity in minors only achieved $66.7 \%$, which is mainly because there were not enough samples of minors included in this study.

Table 4. Model performance of the composite outcome prediction model in different age groups.

\begin{tabular}{lllll}
\hline Metrics & $\begin{array}{l}\text { Minors ( } \leq 18 \text { years }) \\
(\mathrm{N}=29)\end{array}$ & $\begin{array}{l}\text { Youth (19-44 years) } \\
(\mathrm{N}=502)\end{array}$ & $\begin{array}{l}\text { Middle aged (45-59 years) } \\
(\mathrm{N}=406)\end{array}$ & $\begin{array}{l}\text { Elderly }(\geq 60 \text { years }) \\
(\mathrm{N}=293)\end{array}$ \\
\hline AUC $^{\mathrm{a}}$ & 0.833 & 0.943 & 0.912 & 0.895 \\
Accuracy, \% & 89.7 & 92.0 & 82.3 & 80.9 \\
Sensitivity, \% & 66.7 & 89.1 & 87.3 & 82.2 \\
Specificity, \% & 92.3 & 92.3 & 81.2 & 80.5 \\
Precision, \% & 50.0 & 53.9 & 49.6 & 58.3 \\
\hline
\end{tabular}

${ }^{\mathrm{a}} \mathrm{AUC}$ : area under the receiver-operating characteristic curve.

\section{Discussion}

\section{Principal Results}

Based on the EMRs from Fuwai Hospital, we developed 5 prediction models with good performance for 4 etiologies of secondary hypertension using XGBoost. Validation of the composite outcome prediction model achieved an AUC of 0.924, while the 4 prediction models of the secondary hypertension etiologies achieved AUCs of 0.938-0.965 in the validation data set. The observed model performance suggested that it was feasible to derive effective ML prediction models of secondary hypertension, which may play important roles in predicting etiologies of patients with suspected secondary hypertension. 


\section{Comparison With Prior Work}

With the accumulation, integration, and standardization of medical information, as well as the constant improvement of computing power, the potential uses for AI in medicine are growing [40]. AI-assisted diagnosis is a very important medical application field and its application in hypertension has gained attention [22-27]. Some studies of AI technologies in the prediction and diagnosis of hypertension or primary hypertension have been published; for instance, a real-time risk prediction model of future 1-year incident essential hypertension using XGBoost has been deployed in Maine, providing inspiration for hypertension and related disease intervention [26]. Detection of secondary hypertension is of great significance in the clinical diagnosis and treatment of hypertension. Chinese guidelines for the prevention and treatment of hypertension state that all patients with hypertension need undergo the assessment of secondary hypertension [4]. Nonetheless, no studies regarding AI-assisted diagnosis in secondary hypertension have been published yet. Our study filled this gap and will potentially be useful in enhancing the detection of etiologies of secondary hypertension.

All patients included in this study needed to consider the possibility of secondary hypertension according to the admission criteria of patients with hypertension in Fuwai Hospital, which ensured that the prediction models were applicable to detection of extensive etiologies of secondary hypertension [7]. Compared to ML prediction models in previous similar studies, it can be seen that the prediction models derived from this study showed good performance [41-46]. The models in our study achieved AUCs of 0.924-0.965 in the validation data set. Furthermore, validation of the composite outcome prediction model on different age groups has been performed, which demonstrated high discrimination in all age groups of adults.

Most of the features identified in this study were consistent with those of the previous studies [1,2,4,5,47-51]. It has been reported that the main imaging methods for the diagnosis of renal artery stenosis were $\mathrm{CT}$, magnetic resonance imaging, and ultrasound [5]. Both albumin-to-creatinine ratio and NT-proBNP were important indicators of renal function [47,51], which are also of great significance for RVH prediction in our model. Aldosterone-to-renin ratio was a screening tool for PA $[2,48]$. Our model indicated that serum potassium played an important role in the PA prediction model [4,49]. Besides thyroid disease, thyrotropin and free thyroxine were the core clinical indicators for identification of thyroid dysfunction [1]. One of the main clinical manifestations of aortic stenosis is carotid bruits [4]. In addition, there was a certain correlation between age and aortic stenosis which has been demonstrated in previous studies [1,50].

\section{Application of the Prediction Models}

Application of ML methods to etiological diagnosis of secondary hypertension can be useful in clinical practice. As the use of EMRs is becoming increasingly common in hospitals, it is convenient to obtain an individual's integrated clinical data [26]. ML algorithms can comprehensively analyze all the obtained information of patients, and will be more targeted and flexible than traditional guidelines. AI technology should be implemented cautiously, as to be partners, or even mentors of clinicians, there is still a long way to go, but it can serve as a virtual assistant and enable clinicians to promote quality and improve efficiency. The ML prediction models derived from our study hold promise for developing a diagnostic tool for detection of secondary hypertension and integration into EMR systems to offer real-time clinical support. Model reasoning will be invoked automatically and the most probable etiology of secondary hypertension will be recommended for clinical reference. Moreover, it will be of great significance to apply the diagnostic models, based on big data of authoritative medical institutions, to community medical institutions. The practice results manifested that the models developed in this study have the potential to realize this vision after further optimization and prospective verification.

\section{Limitations}

There are several limitations of this study. It is worth noting that not all common secondary hypertension etiologies were covered in this study; however, we are making efforts to accumulate more data and expand the samples and indicators to accomplish and add more etiological prediction models. Direct text analysis for extracting CT features is language specific; therefore, the models must be adapted and revised before using them in a different language setting. Lastly, more external validations are in need and will be performed with more different data sets.

\section{Conclusions}

Based on the EMRs from Fuwai Hospital, 5 ML prediction models with good performance and applicable to etiologies detection of secondary hypertension in all age groups of adults were developed, which demonstrated that ML approaches were feasible and effective in the diagnosis of secondary hypertension. Such prediction models have the potential to help clinical decision making which may augment and extend effectiveness of the clinicians and help to develop more intelligent, more efficient, and more convenient hypertension diagnosis modes. However, these innovative and clinically relevant prediction models still require further validation and more clinical tests before being implemented into clinical practice.

\section{Acknowledgments}

This work was supported by 2 programs of Chinese Academy of Medical Sciences (CRFH20170009, 2018-I2M-AI-006).

\section{Authors' Contributions}

$\mathrm{XD}$ and $\mathrm{YH}$ carried out the deep analysis and interpretation of data, finished the development and optimization of prediction models, and drafted and revised the initial manuscript. ZY completed initial analysis and modeling attempts. HW, JY, and YW coordinated and supervised data acquisition and data quality control. JC and WZ conceptualized and designed the study and 
critically reviewed and revised the manuscript. All authors have read and approved this submission for publication. All authors have agreed to be accountable for all aspects of the work.

\section{Conflicts of Interest}

None declared.

\section{Multimedia Appendix 1}

The final 79 clinical indicators included in 5 prediction models and their contributions in each model. ARR: aldosterone-to-renin ratio; CT: computed tomography; NT-proBNP: N-terminal pro-brain natriuretic peptide; PA: primary aldosteronism; RVH: renovascular hypertension.

[XLSX File (Microsoft Excel File), 15 KB-Multimedia Appendix 1]

\section{References}

1. Charles L, Triscott J, Dobbs B. Secondary Hypertension: Discovering the Underlying Cause. Am Fam Physician 2017 Oct 01;96(7):453-461 [FREE Full text] [Medline: 29094913]

2. Puar THK, Mok Y, Debajyoti R, Khoo J, How CH, Ng AKH. Secondary hypertension in adults. Singapore Med J 2016 May;57(5):228-232 [FREE Full text] [doi: 10.11622/smedj.2016087] [Medline: 27211205]

3. Rimoldi SF, Scherrer U, Messerli FH. Secondary arterial hypertension: when, who, and how to screen? Eur Heart J 2014 May 14;35(19):1245-1254. [doi: 10.1093/eurheartj/eht534] [Medline: 24366917]

4. Committee of Revision of Chinese Guidelines for Hypertension Prevention and Control, et al. 2018 Chinese guidelines for the management of hypertension. Chinese Journal of Cardiovascular Medicine 2019;24(01):24-56. [doi: 10.3969/j.issn.1007-5410.2019.01.002]

5. Expert Panels on Urologic Imaging and Vascular Imaging, Harvin HJ, Verma N, Nikolaidis P, Hanley M, Dogra VS, et al. ACR Appropriateness Criteria ${ }^{\circledR}$ Renovascular Hypertension. J Am Coll Radiol 2017 Nov;14(11S):S540-S549. [doi: 10.1016/j.jacr.2017.08.040] [Medline: 29101991]

6. Gupta-Malhotra M, Banker A, Shete S, Hashmi SS, Tyson JE, Barratt MS, et al. Essential hypertension vs. secondary hypertension among children. Am J Hypertens 2015 Jan;28(1):73-80 [FREE Full text] [doi: 10.1093/ajh/hpu083] [Medline: 24842390]

7. Liu X, Cai J, Ma W, Lou Y, Hao S, Bian J, et al. Analysis of etiology and target organ damage in hospitalized patients with hypertension. Chinese Journal of Hypertension 2019 Mar;027(003):229-234. [doi: 10.16439/j.cnki.1673-7245.2019.03.011]

8. Handelman GS, Kok HK, Chandra RV, Razavi AH, Lee MJ, Asadi H. eDoctor: machine learning and the future of medicine. J Intern Med 2018 Dec;284(6):603-619. [doi: 10.1111/joim.12822] [Medline: $\underline{\text { 30102808] }}$

9. Topol EJ. High-performance medicine: the convergence of human and artificial intelligence. Nat Med 2019 Jan;25(1):44-56. [doi: 10.1038/s41591-018-0300-7] [Medline: 30617339]

10. Johnson KW, Torres Soto J, Glicksberg BS, Shameer K, Miotto R, Ali M, et al. Artificial Intelligence in Cardiology. J Am Coll Cardiol 2018 Jun 12;71(23):2668-2679 [FREE Full text] [doi: 10.1016/j.jacc.2018.03.521] [Medline: 29880128]

11. Poh MZ, Poh YC, Chan PH, Wong CK, Pun L, Leung WW, et al. Diagnostic assessment of a deep learning system for detecting atrial fibrillation in pulse waveforms. Heart 2018 May 31. [doi: 10.1136/heartjnl-2018-313147] [Medline: 29853485]

12. Ardila D, Kiraly AP, Bharadwaj S, Choi B, Reicher JJ, Peng L, et al. End-to-end lung cancer screening with three-dimensional deep learning on low-dose chest computed tomography. Nat Med 2019 Jun;25(6):954-961. [doi: 10.1038/s41591-019-0447-x] [Medline: 31110349]

13. De Fauw J, Ledsam JR, Romera-Paredes B, Nikolov S, Tomasev N, Blackwell S, et al. Clinically applicable deep learning for diagnosis and referral in retinal disease. Nat Med 2018 Dec;24(12):1342-1350. [doi: 10.1038/s41591-018-0107-6] [Medline: 30104768 ]

14. Piazza G, Hurwitz S, Galvin CE, Harrigan L, Baklla S, Hohlfelder B, et al. Alert-based computerized decision support for high-risk hospitalized patients with atrial fibrillation not prescribed anticoagulation: a randomized, controlled trial (AF-ALERT). Eur Heart J 2020 Mar 07;41(10):1086-1096. [doi: 10.1093/eurheartj/ehz385] [Medline: 31228189]

15. Pang S, Wang S, Rodríguez-Patón A, Li P, Wang X. An artificial intelligent diagnostic system on mobile Android terminals for cholelithiasis by lightweight convolutional neural network. PLoS One 2019 Sep 12;14(9):e0221720 [FREE Full text] [doi: 10.1371/journal.pone.0221720] [Medline: 31513631]

16. Wu X, Huang Y, Liu Z, Lai W, Long E, Zhang K, et al. Universal artificial intelligence platform for collaborative management of cataracts. Br J Ophthalmol 2019 Nov;103(11):1553-1560 [FREE Full text] [doi: 10.1136/bjophthalmol-2019-314729] [Medline: 31481392]

17. Wang X, Zhang Y, Hao S, Zheng L, Liao J, Ye C, et al. Prediction of the 1-Year Risk of Incident Lung Cancer: Prospective Study Using Electronic Health Records from the State of Maine. J Med Internet Res 2019 May 16;21(5):e13260 [FREE Full text] [doi: 10.2196/13260] [Medline: 31099339] 
18. Ye C, Wang O, Liu M, Zheng L, Xia M, Hao S, et al. A Real-Time Early Warning System for Monitoring Inpatient Mortality Risk: Prospective Study Using Electronic Medical Record Data. J Med Internet Res 2019 Jul 05;21(7):e13719 [FREE Full text] [doi: 10.2196/13719] [Medline: 31278734]

19. Wu J, Qiu J, Xie E, Jiang W, Zhao R, Qiu J, et al. Predicting in-hospital rupture of type A aortic dissection using Random Forest. J Thorac Dis 2019 Nov;11(11):4634-4646 [FRE Full text] [doi: 10.21037/jtd.2019.10.82] [Medline: 31903252$]$

20. Tomašev N, Glorot X, Rae JW, Zielinski M, Askham H, Saraiva A, et al. A clinically applicable approach to continuous prediction of future acute kidney injury. Nature 2019 Aug;572(7767):116-119. [doi: 10.1038/s41586-019-1390-1] [Medline: 31367026]

21. Zhao J, Feng Q, Wu P, Lupu RA, Wilke RA, Wells QS, et al. Learning from Longitudinal Data in Electronic Health Record and Genetic Data to Improve Cardiovascular Event Prediction. Sci Rep 2019 Jan 24;9(1):717 [FREE Full text] [doi: 10.1038/s41598-018-36745-x] [Medline: 30679510]

22. Sakr S, Elshawi R, Ahmed A, Qureshi WT, Brawner C, Keteyian S, et al. Using machine learning on cardiorespiratory fitness data for predicting hypertension: The Henry Ford ExercIse Testing (FIT) Project. PLoS One 2018 Apr 18;13(4):e0195344 [FREE Full text] [doi: 10.1371/journal.pone.0195344] [Medline: 29668729]

23. Elshawi R, Al-Mallah MH, Sakr S. On the interpretability of machine learning-based model for predicting hypertension. BMC Med Inform Decis Mak 2019 Jul 29;19(1):146 [FREE Full text] [doi: 10.1186/s12911-019-0874-0] [Medline: 31357998]

24. Heo BM, Ryu KH. Prediction of Prehypertenison and Hypertension Based on Anthropometry, Blood Parameters, and Spirometry. Int J Environ Res Public Health 2018 Nov 16;15(11):2571 [FREE Full text] [doi: 10.3390/ijerph15112571] [Medline: 30453592]

25. Krittanawong C, Bomback AS, Baber U, Bangalore S, Messerli FH, Wilson Tang WH. Future Direction for Using Artificial Intelligence to Predict and Manage Hypertension. Curr Hypertens Rep 2018 Jul 06;20(9):75. [doi: 10.1007/s11906-018-0875-x] [Medline: 29980865]

26. Ye C, Fu T, Hao S, Zhang Y, Wang O, Jin B, et al. Prediction of Incident Hypertension Within the Next Year: Prospective Study Using Statewide Electronic Health Records and Machine Learning. J Med Internet Res 2018 Jan 30;20(1):e22 [FREE Full text] [doi: 10.2196/jmir.9268] [Medline: 29382633]

27. Park J, Kim J, Ryu B, Heo E, Jung SY, Yoo S. Patient-Level Prediction of Cardio-Cerebrovascular Events in Hypertension Using Nationwide Claims Data. J Med Internet Res 2019 Feb 15;21(2):e11757 [FREE Full text] [doi: 10.2196/11757] [Medline: $\underline{30767907]}$

28. Koren G, Nordon G, Radinsky K, Shalev V. Machine learning of big data in gaining insight into successful treatment of hypertension. Pharmacol Res Perspect 2018 Apr 24;6(3):e00396 [FREE Full text] [doi: 10.1002/prp2.396] [Medline: 29721321]

29. Silveira DV, Marcolino MS, Machado EL, Ferreira CG, Alkmim MBM, Resende ES, et al. Development and Evaluation of a Mobile Decision Support System for Hypertension Management in the Primary Care Setting in Brazil: Mixed-Methods Field Study on Usability, Feasibility, and Utility. JMIR Mhealth Uhealth 2019 Mar 25;7(3):e9869 [FREE Full text] [doi: 10.2196/mhealth.9869] [Medline: 30907740]

30. Kim HY, Kim JH, Cho I, Lee JH, Kim Y. Verification \& validation of the knowledge base for the hypertension management CDSS. Stud Health Technol Inform 2010;160(Pt 2):1140-1144. [Medline: 20841862]

31. Martins SB, Lai S, Tu S, Shankar R, Hastings SN, Hoffman BB, et al. Offline testing of the ATHENA Hypertension decision support system knowledge base to improve the accuracy of recommendations. AMIA Annu Symp Proc 2006:539-543 [FREE Full text] [Medline: 17238399]

32. Duru F. Fuwai Hospital, Beijing, China: The World's Largest Cardiovascular Science Centre with more than 1200 beds. Eur Heart J 2018 Mar 07;39(6):428-429. [doi: 10.1093/eurheartj/ehx804] [Medline: 29425349]

33. Lantz B. Machine Learning with R. Birmingham, UK: Packt Publishing; 2013.

34. Chawla NV, Bowyer KW, Hall LO, Kegelmeyer WP. SMOTE: Synthetic Minority Over-sampling Technique. jair 2002 Jun 01;16:321-357. [doi: 10.1613/jair.953]

35. Chen T, Guestrin C. XGBoost: A Scalable Tree Boosting System. In: Proceedings of the 22nd ACM SIGKDD International Conference on Knowledge Discovery and Data Mining. 2016 Presented at: 22nd ACM SIGKDD International Conference on Knowledge Discovery and Data Mining; August 16 and 17, 2016; San Francisco, CA. [doi: 10.1145/2939672.2939785]

36. Huang C, Murugiah K, Mahajan S, Li S, Dhruva SS, Haimovich JS, et al. Enhancing the prediction of acute kidney injury risk after percutaneous coronary intervention using machine learning techniques: A retrospective cohort study. PLoS Med 2018 Nov;15(11):e1002703 [FREE Full text] [doi: 10.1371/journal.pmed.1002703] [Medline: 30481186]

37. Hernesniemi JA, Mahdiani S, Tynkkynen JA, Lyytikäinen L, Mishra PP, Lehtimäki T, et al. Extensive phenotype data and machine learning in prediction of mortality in acute coronary syndrome - the MADDEC study. Ann Med 2019 Mar;51(2):156-163. [doi: 10.1080/07853890.2019.1596302] [Medline: $\underline{\text { 31030570] }}$

38. Nishio M, Nishizawa M, Sugiyama O, Kojima R, Yakami M, Kuroda T, et al. Computer-aided diagnosis of lung nodule using gradient tree boosting and Bayesian optimization. PLoS One 2018;13(4):e0195875 [FREE Full text] [doi: 10.1371/journal.pone.0195875] [Medline: 29672639] 
39. Ma X, Wu Y, Zhang L, Yuan W, Yan L, Fan S, et al. Comparison and development of machine learning tools for the prediction of chronic obstructive pulmonary disease in the Chinese population. J Transl Med 2020 Mar 31;18(1):146 [FREE Full text] [doi: 10.1186/s12967-020-02312-0] [Medline: $\underline{\text { 32234053] }}$

40. Lee CS, Lee AY. Clinical applications of continual learning machine learning. The Lancet Digital Health 2020 Jun;2(6):e279-e281. [doi: 10.1016/s2589-7500(20)30102-3]

41. Li S, Jiang H, Wang Z, Zhang G, Yao Y. An effective computer aided diagnosis model for pancreas cancer on PET/CT images. Comput Methods Programs Biomed 2018 Oct;165:205-214. [doi: 10.1016/j.cmpb.2018.09.001] [Medline: 30337075]

42. Lee JH, Ha EJ, Kim JH. Application of deep learning to the diagnosis of cervical lymph node metastasis from thyroid cancer with CT. Eur Radiol 2019 Oct;29(10):5452-5457. [doi: 10.1007/s00330-019-06098-8] [Medline: 30877461]

43. Gunčar G, Kukar M, Notar M, Brvar M, Černelč P, Notar M, et al. An application of machine learning to haematological diagnosis. Sci Rep 2018 Jan 11;8(1):411 [FREE Full text] [doi: 10.1038/s41598-017-18564-8] [Medline: 29323142]

44. Wang G, Teoh J, Choi K. Diagnosis of prostate cancer in a Chinese population by using machine learning methods. Annu Int Conf IEEE Eng Med Biol Soc 2018 Jul;2018:1-4. [doi: 10.1109/EMBC.2018.8513365] [Medline: 30440319]

45. Wang H, Wang Y, Liang C, Li Y. Assessment of Deep Learning Using Nonimaging Information and Sequential Medical Records to Develop a Prediction Model for Nonmelanoma Skin Cancer. JAMA Dermatol 2019 Sep 04;155(11):1277-1283. [doi: 10.1001/jamadermatol.2019.2335] [Medline: 31483437]

46. Than MP, Pickering JW, Sandoval Y, Shah ASV, Tsanas A, Apple FS, MI3 collaborative. Machine Learning to Predict the Likelihood of Acute Myocardial Infarction. Circulation 2019 Aug 16 [FREE Full text] [doi: 10.1161/CIRCULATIONAHA.119.041980] [Medline: 31416346]

47. Gao P, Zhu Q, Bian S, Liu H, Xie H. Prognostic value of plasma NT-proBNP levels in very old patients with moderate renal insufficiency in China. Z Gerontol Geriatr 2018 Dec;51(8):889-896 [FREE Full text] [doi: 10.1007/s00391-017-1327-y] [Medline: 29058070]

48. Adrenal group of Chinese Society of Endocrinology. Expert consensus on diagnosis and treatment of primary aldosteronism. Chinese Journal of Endocrinology and Metabolism 2016 Mar;32(3):188-195. [doi: 10.3760/cma.j.issn.1000-6699.2016.03.003]

49. Chioncel V, Păun D, Amuzescu B, Sinescu C. Evolution features of hypertensive patients with primary aldosteronism--prospective study. J Med Life 2012 Sep 15;5(3):354-359 [FREE Full text] [Medline: 23049641]

50. Joseph J, Naqvi SY, Giri J, Goldberg S. Aortic Stenosis: Pathophysiology, Diagnosis, and Therapy. Am J Med 2017 Mar;130(3):253-263. [doi: 10.1016/j.amjmed.2016.10.005] [Medline: 27810479]

51. Jin Y, Zhang Q, Guo Y. Microalbunminuria. Chinese Journal of Hypertension 2009 Mar;017(003):283-286. [doi: 10.16439/j.cnki.1673-7245.2009.03.003]

\section{Abbreviations}

AI: artificial intelligence

AUC: area under the receiver-operating characteristic curve

BP: blood pressure

CT: computed tomography

EMR: electronic medical record

ICD-10-CM: International Classification of Diseases, 10th Revision, Clinical Modification

ML: machine learning

NT-proBNP: N-terminal pro-brain natriuretic peptide

PA: primary aldosteronism

RVH: renovascular hypertension

XGBoost: extreme Gradient Boosting

Edited by G Eysenbach; submitted 30.04.20; peer-reviewed by J Triscott, N Anegondi; comments to author $12.06 .20 ;$ revised version
received 16.09.20; accepted 28.10.20; published 25.01.21
Please cite as:
Diao X, Huo Y, Yan Z, Wang H, Yuan J, Wang Y, Cai J, Zhao W
An Application of Machine Learning to Etiological Diagnosis of Secondary Hypertension: Retrospective Study Using Electronic
Medical Records
JMIR Med Inform 2021;9(1):e19739
URL: $\underline{\text { http://medinform.jmir.org/2021/1/e19739/ }}$
doi: $\underline{10.2196 / 19739}$
PMID: $\underline{3492233}$


(CXiaolin Diao, Yanni Huo, Zhanzheng Yan, Haibin Wang, Jing Yuan, Yuxin Wang, Jun Cai, Wei Zhao. Originally published in JMIR Medical Informatics (http://medinform.jmir.org), 25.01.2021. This is an open-access article distributed under the terms of the Creative Commons Attribution License (https://creativecommons.org/licenses/by/4.0/), which permits unrestricted use, distribution, and reproduction in any medium, provided the original work, first published in JMIR Medical Informatics, is properly cited. The complete bibliographic information, a link to the original publication on http://medinform.jmir.org/, as well as this copyright and license information must be included. 